\title{
colômbia: Mais Insegurança Humana, Menos Segurança Regional*
}

\author{
Juan Gabriel Tokatlian
}

\section{Introdução}

\begin{abstract}
A região andina atravessa hoje uma crise profunda, de conseqüências imprevisíveis. A Colômbia é apenas a ponta do iceberg de um enorme bloco de problemas acumulados em sua manifestação e protelados em sua solução. Na realidade, os Andes converteram-se, a partir dos anos 90 e neste começo de século, no maior foco de instabilidade e inquietude do Continente. Em matéria política, destaca-se o autogolpe de Alberto Fujimori no Peru, a queda constitucional de Carlos A. Pérez na Venezuela, a saída política de Abdalá Bucaram no Equador, a quase-derrocada de Ernesto Samper na Colômbia e a chegada ao poder do ex-golpista Hugo Banzer na Bolívia. O descalabro social que levou à derrubada de facto de Jamil Mahuad no Equador, a ambição autoritária da cleptocracia estabelecida por $\mathrm{Fu}-$ jimori no Peru, a delicada incerteza institucional gerada por Hugo
\end{abstract}

\footnotetext{
*Tradução de Marisa Gandelman - marisa@ copygan.com.br
}

CONTEXTO INTERNACIONAL Rio de Janeiro, vol. 24, no 1, janeiro/junho 2002, pp. 129-166. 


\section{Juan Gabriel Tokatlian}

Chávez na Venezuela, os crescentes inconvenientes de todo tipo que vive a Bolívia, a situação explosiva que enfrenta Andrés Pastrana na Colômbia, são indicadores eloqüentes de que os Andes estão vivendo um turbilhão.

Em matéria militar, o maior enfrentamento limítrofe do hemisfério se deu entre Equador e Peru, e a fronteira mais tensa do Continente, no momento, é a da Colômbia com a Venezuela. No que se refere aos direitos humanos, e em comparação com qualquer outra região da América, a zona andina é aquela onde estes são violados mais sistematicamente, sendo os casos da Colômbia e do Peru os mais dramáticos. Na questão das drogas, os Andes concentram o cultivo, o processamento e o tráfico de cocaína do Continente e as cinco nações (junto com o México) são os atores-chave no negócio ilícito de narcóticos. Em matéria de corrupção, na área são encontrados alguns dos países com os mais altos níveis do mundo, destacando-se Bolívia, Equador e Venezuela.

No tema ambiental, os países andinos apresentam níveis de degradação altos e preocupantes, especialmente no espaço amazônico que compartilham com o Brasil. Em termos socioeconômicos, todas as nações exibem índices alarmantes de desemprego, marginalidade, pobreza e insegurança, com baixos indicadores de qualidade de vida, crescimento escasso e volátil, forte concentração de renda e exíguo investimento. Nos cinco países, igualmente, ainda que com algumas variações, o desmoronamento parcial do Estado exacerbou-se na última década.

Além disso, no cenário pós-Guerra Fria, é na região andina (particularmente no Equador, Peru e Venezuela) que os militares têm conservado sua maior influência política e tendência corporativa. Da mesma forma, a Comunidade Andina de Nações (CAN) está cada dia mais retraída. Por último, o mundo andino está mais e mais dependente de Washington nos aspectos material e político e mais e mais 
distante do Cone Sul nas dimensões cultural e diplomática. A esfera de influência ${ }^{1}$ dos Estados Unidos está se deslocando de seu tradicional mare nostrum - a ampla baía do Caribe - e se projeta com mais força no vértice andino do Continente sul-americano.

Resumindo, toda a região andina sofre, simultaneamente, problemas agudos de diversas naturezas. Os conflitos sociais na área tendem a aumentar e é clara a incapacidade dos regimes democráticos para processar demandas seculares da cidadania insatisfeita. Nesse contexto, o caso da Colômbia é, sem dúvida, o mais catastrófico. A Colômbia sobressai na dimensão de sua crise, mesmo que não seja um exemplo isolado: os Andes vivem em condições de ingovernabilidade que pressagiam cataclismos institucionais perigosos.

Sendo assim, o tratamento a ser dado à crise da Colômbia servirá potencialmente de modelo de intervenção externa em assuntos do hemisfério. Da mesma forma, lá se coloca em jogo como e quanto nossa área (América Latina), região (América do Sul) ou zona (Cone Sul) contribuirão para a solução do problema. O exemplo mais difícil - a Colômbia - deve ser enfrentado e não evitado: só assim será possível observar se a diplomacia de nossos países amadureceu o suficiente para enfrentar com maior autonomia relativa os desafios do novo século.

\section{A Natureza da Guerra}

O conflito armado na Colômbia pode ser analisado de perspectivas distintas. Aqui, destaco dois pontos de vista: um a partir do Estado e o outro da própria guerra. Para um número crescente de analistas nacionais e estrangeiros, o país andino vem vivenciando um desmoronamento do Estado comparável ao que precipitou a experiência conhecida como a Violência, porém ainda mais peculiar e complexo. Segundo a expressão cunhada por Oquist sobre o "colapso parcial do Estado" colombiano nos anos 40 e 50, as "articulações concretas" - 


\section{Juan Gabriel Tokatlian}

internas e exógenas - que o caracterizaram foram: 1) a "quebra das instituições políticas estabelecidas"; 2) a "perda de legitimidade do Estado"; 3) as "contradições dentro do Estado"; 4) a "ausência física do Estado" (ver Oquist, 1978). Com exceção do fator de número três, e apesar das reformas introduzidas na Constituição de 1991, os outros fatores emergiram com força a partir de meados dos anos 70, e vêm se consolidando no início do século XXI.

Se adotarmos uma definição mais recente de Estado em colapso (collapsed state), este se caracterizaria pela implosão das estruturas de autoridade e legitimidade (ver, entre outros, Zartman, 1995; Reno, 2000). Dá-se, então, um fenômeno de ingovernabilidade produzido pela articulação entre forças internas e pressões externas. Guerra e crime simultâneos no plano interno, conjugados com o Plano Colômbia e a Iniciativa Andina concorrentes no âmbito externo, constituem uma combinação fatal. No meu entender, a Colômbia, que não é um caso inédito ou excepcional, caminha em direção a essa condição de colapso.

Tudo isso levará o país, mais cedo do que tarde, a testemunhar um Estado fracassado (failed state), isto é, um Estado incapaz de proteger seus indivíduos e comunidades das forças que ameaçam a sua integridade $^{2}$. Nesse sentido, a Colômbia não tem um Estado anárquico (ausência completa de governo central), mas vive sim, no momento, uma mistura de Estado-fantasma (que exerce a autoridade em algumas áreas limitadas e em outras é inexistente) e Estado anêmico (suas energias são consumidas no combate a diversas modalidades de grupos armados).

Nesse contexto, vale lembrar que, de acordo com um dos principais relatórios da United States Commission on National Security/21st Century, co-liderada por Gary Hart e Warren Rudman, os Estados Unidos devem estabelecer prioridades diante da eventualidade de uma expansão do fenômeno dos failed states. 
"Nem todos os problemas desse tipo têm de ser antes de tudo responsabilidade dos Estados Unidos, particularmente em um mundo onde outros poderes estão acumulando riqueza e recursos humanos significativos. Existem países cuja estabilidade doméstica é, por diferentes razões, da maior importância para os interesses dos Estados Unidos (tais como México, Colômbia, Rússia e Arábia Saudita). Sem prejulgar a probabilidade de levante doméstico, esses países deveriam ser um foco prioritário do planejamento dos Estados Unidos de forma apropriada aos respectivos casos. Para casos de menos prioridade, os Estados Unidos deveriam ajudar a comunidade internacional a desenvolver mecanismos inovadores para lidar com os problemas de Estados fracassados."

De acordo com especialistas que definem formas distintas de Estado que apresentam instabilidade interna aguda, a Colômbia não tem um Estado anárquico (ausência completa de governo central), porém está se transformando em um Estado fracassado, ou seja, incapaz de proteger seus indivíduos e comunidades das forças que ameaçam a segurança de sua existência. Parece claro que o país não vive uma revolução política e popular, nem uma rebelião de cidadania e justiça contra um Estado robusto e dominante. Estamos diante muito mais de uma revolta amorfa e desequilibrada de um complexo amálgama de setores emergentes inconformados, excluídos e esquecidos. Uma revolta que é canalizada parcial e contraditoriamente por grupos armados poderosos que, apesar de carecerem de um projeto unívoco, afirmam sua influência social, seu controle territorial e sua projeção política através do colapso inacabado do Estado e da agonia da sociedade desarmada. Trata-se de uma agitação violenta e difusa, impulsionada igualmente por movimentos guerrilheiros, máfias organizadas e grupos reacionários, que parecem ter força suficiente para encurralar o Estado, mas que não possuem capacidade para construir uma nova autoridade.

A perspectiva de equilíbrio que caracteriza a reflexão em torno da legitimidade não parece útil neste caso. Não há um projeto homogêneo que cresce em legitimidade enquanto outro decresce, compensando assim uma situação de altos e baixos em termos do que é legítimo e 
ilegítimo. Não existe uma elite tradicional, predominante e esclarecida, nem um contrapoder compacto, vigoroso e civilizador. Assistimos sim a legitimidades degradadas, tanto as existentes como as desafiantes. Presenciamos o perigoso fracasso do Estado de Direito e a ausência de um horizonte alternativo com capacidade para estabelecer a ordem, a paz e o bem-estar. Por isso, o que predomina é a mistura de guerra política, violência criminal e violação humanitária.

Esse conflito está cada vez mais emaranhado, o que não significa, sem dúvida, que seja indecifrável. Nesse sentido, é pertinente ressaltar algumas tendências nítidas. A guerra irregular que predomina há décadas na Colômbia vem ampliando seu espaço de manifestação e por isso vem se transformando em guerra civil, com grupos fortemente armados liderando projetos ideológicos polarizados e bases de sustentação social próprias.

Desse modo, a guerra política assume crescentemente aspectos de uma guerra criminal. Cada vez mais os atores armados vão degradando seu perfil político, vão abandonando práticas sustentadas em princípios e assumindo comportamentos delinqüentes. Além disso, o conflito colombiano é mais que o somatório de guerras locais díspares e contraditórias, o país está atravessando uma guerra nacional, isto é, as disputas não estão circunscritas a uma racionalidade unicamente regional, mas adquirem a lógica de um confronto que se estende por todo o território. Nesse contexto, enquanto os enfrentamentos rurais continuam e se exacerbam em mais zonas do país, a contenda vem se instalando em novos âmbitos urbanos.

Paralelamente, a guerra na Colômbia deixou de ser doméstica. O paulatino, preciso e persistente envolvimento dos Estados Unidos no conflito interno vem convertendo o país no epicentro de uma guerra de baixa intensidade cada vez mais internacionalizada. Por último, a guerra colombiana já não é mais limitada em termos de vítimas, parti- 
cipantes armados e alcance. Os dados não podem ser mais eloqüentes $^{3}$.

No que se refere à última década, o nível de violência política alcança a cifra de quase dez mortos por dia. Aproximadamente, 120 municípios ( $12 \%$ do total) estão totalmente destruídos pelas guerrilhas. Somente no biênio 1998-2000 ocorreram mais de quinhentos massacres (assassinato coletivo de quatro ou mais pessoas indefesas), em sua grande maioria cometidos por paramilitares. Dos anos 80 para cá, o número de desaparecidos por motivos políticos supera 4 mil somente em 2000 ocorreram 743 desaparecimentos. Entre 1995 e 2000, foram levados a cabo 12 mil sequiestros a mando de atores armados, da criminalidade comum e até dos corpos de segurança do Estado. Em toda a década de 90, a cifra de homicídios superou os 250 mil. Desde 1996 já se deu um êxodo para o exterior de quase 350 mil colombianos. Nos últimos quinze anos foi produzido um deslocamento interno forçado de mais de 1,8 milhão de pessoas. Entre assassinados, mutilados, seqüestrados, deslocados e recrutados, mais de 1 milhão de crianças são vítimas da guerra. A grande maioria desses fatos permanece impune. Na verdade, a guerra colombiana produziu, produz e continuará produzindo uma angustiante e descontrolada insegurança que afeta, principalmente, a população civil não-combatente.

Esse instável, complexo e crítico estado de conflito na Colômbia vem fomentando a ingerência dos Estados Unidos nos assuntos do país. Não há unanimidade nos Estados Unidos, nem consenso definitivo entre este país e a América Latina, sobre a melhor saída para o conflito armado colombiano. Existe sim um relativo acordo, em particular entre os países vizinhos, sobre os potenciais efeitos negativos para o Continente da situação que esse país andino atravessa.

Com o tácito consentimento latino-americano, que se evidencia pelo notório silêncio regional, Washington vem desenvolvendo uma mo- 


\section{Juan Gabriel Tokatlian}

dalidade inédita de intervenção indireta no caso colombiano. Por um lado, observa-se um intervencionismo no velho estilo, típico da Guerra Fria: assim como em certo momento em El Salvador, os Estados Unidos agora apóiam militarmente (assistência, armas, treinamento, informação etc.) um país afetado por guerra interna cada vez mais cruel. A importância geopolítica da Colômbia, sua dimensão territorial, demográfica e econômica, e a combinação de diferentes ameaças (narcotráfico, crime organizado, guerrilha, terrorismo, paramilitarismo) contribuem para que a ajuda dos Estados Unidos a Bogotá se torne maciça e crescente.

Por outro, verifica-se um novo tipo de intervencionismo pós-Guerra Fria: em parte, mediante pressão e apoio (conforme o caso) aos países limítrofes para criarem um "cordão sanitário" diplomático e militar ao redor da Colômbia; em parte, por via do desenvolvimento de planos contingenciais para um potencial uso da força, com a eventual participação de países amigos de Washington.

Esse modelo dual se vem aperfeiçoando nos últimos anos e tem vários componentes, dentre os quais cabe ressaltar: o aumento da ajuda de segurança à Colômbia; a relevância que se dá ao perfil de "país-problema" da Colômbia no âmbito do hemisfério e internacional; o crescimento de uma diplomacia regional destinada a mobilizar os países da área em torno de estratégias de contenção do fenômeno colombiano; e o incremento de uma retórica oficial unificada em torno da presença de uma inexorável ameaça "narco-guerrilheira" na Colômbia.

Potencialmente, esse novo intervencionismo na Colômbia pode adotar três formas: $1^{\text {a }}$ ) "intervenção por imposição" - contra a vontade dos colombianos, e apesar dos esforços de negociação interna, Washington concretiza uma coalizão ad hoc que decide se envolver militarmente no país para estabelecer uma nova "ordem"; $2^{a}$ ) "intervenção por deserção" - o fato de o Estado colombiano não poder conter o conflito armado interno e nem mesmo garantir a sua soberania, serve de 
desculpa para que Washington encabece uma coalizão interventora temporária, até que o poder estabelecido em Bogotá se fortaleça; $3^{\mathbf{a}}$ ) "intervenção por convite" - um governo eleito solicita a colaboração externa diante da impossibilidade de preservar, de modo autônomo, a ordem interna, a unidade nacional e a institucionalidade democrática. Assim, militares colombianos, mais as forças estrangeiras dirigidas pelos Estados Unidos e compostas por vários países do hemisfério, atuariam conjuntamente para evitar uma implosão nacional. Mesmo que hoje esses cenários despertem uma rejeição justificada, não se deve desconsiderar a probabilidade política de que algum deles se desenhe seriamente, sendo o último o menos improvável.

Em suma, apesar da natureza desregrada da guerra colombiana, que somada ao intervencionismo dos Estados Unidos no país vem constituindo um grave problema de segurança regional, os países latino-americanos, em geral, parecem impávidos em face dessa explosiva combinação de fenômenos.

\section{O Plano Colômbia dos Estados Unidos}

Já se encontra em andamento a assistência multimilionária de segurança dos Estados Unidos à Colômbia: em 2000, o Congresso americano autorizou US\$1,319 bilhão para responder a uma guerra interna complexa e desregrada. O componente B do chamado "Plano Colômbia" - concebido em 1999 na Casa de Nariño por sugestão da Casa Branca - aplica-se como resultado de um intenso debate em Washington, de uma leve discussão em Bogotá e de um mutismo preocupante no hemisfério.

O "Plano Colômbia" de US\$ 7,5 bilhões do governo de Andrés Pastrana tem, até agora, três componentes. O componente A, interno, é mais vultoso e tem como objetivo não só reduzir os efeitos negativos da crise que o país vive, através de medidas do Estado de cercamento 
das áreas mais afetadas pela violência, mas também fortalecer a presença institucional no território nacional. Em seu desenho está implícita a idéia da "cenoura" com a comunidade e por meio de uma saída negociada.

O Plano B é a ajuda dos Estados Unidos - Washington oferece mais quantidade de recursos, porém em prazo mais curto e para outro destinatário. Com efeito, entre 1989 e 1999, a Colômbia recebeu US\$ 1,388 bilhão em assistência antidrogas e de segurança ${ }^{5}$. Agora, o país irá receber um montante similar, porém em dois anos, e o receptor principal será o Exército e não a Polícia, como ocorreu na década de 90. Trata-se do "garrote" - complemento da "cenoura". A lógica subjacente é que somente o poder de fogo e uma maior ocupação espacial das Forças Armadas podem equilibrar o poderio territorial crescente da guerrilha e a enorme influência regional do narcotráfico. Se nos últimos dez anos, com todos os recursos de segurança oferecidos à Colômbia pelos Estados Unidos, a violência de todo tipo se elevou como nunca, assim como a violação de direitos humanos e o descontrole da guerra, não há nada que anuncie um próximo biênio em que esses mesmos problemas não se tornem ainda mais agudos ${ }^{6}$.

O "Plano Colômbia" dos Estados Unidos tem alguns elementos precisos. O pacote específico para a Colômbia chega a US\$ 860,3 milhões. Desse total, a assistência militar alcança a cifra de US\$ 519,2 milhões e a ajuda policial US\$123,1 milhões. Em verdade, o plano busca fortalecer as Forças Armadas (três novos batalhões para operar no sul do país, dezesseis helicópteros Blackhawk e trinta helicópteros UH-1H Huey, e melhores instrumentos de combate e comunicação), para que efetivamente assumam uma postura mais ofensiva na guerra, e melhorar a capacidade da Polícia no combate às drogas (dois helicópteros Blackhawk e doze helicópteros $U H$ - $1 H$ Huey, treinamento para trabalhos de pulverização de produtos químicos para destruir as plantações etc.). Outras categorias contempladas são: desenvolvimento alternativo (US\$ 68,5 milhões), ajuda aos deslocados pela 
guerra (US\$ 37,5 milhões), direitos humanos (US\$ 51 milhões), reforma judicial (US\$ 13 milhões), aplicação da lei (US $\$ 45$ milhões) e paz (US\$ 3 milhões). O restante do pacote de US\$1,319 bilhão - isto é, US\$ 467,8 milhões - desdobra-se em duas grandes categorias: ajuda a países vizinhos da Colômbia (US\$ 180 milhões) e recursos para serem usados diretamente por autoridades norte-americanas (US\$ 287,8 milhões). A respeito desta última categoria, US\$276,8 milhões são para o Departamento de Defesa (melhoramento das bases no Equador, Aruba e Curaçau; programas de inteligência rotineiros e classificados; equipamento de radares, entre outros). Se o total do pacote for decomposto em seus diversos elementos, destinatários e propósitos, tem-se que, aproximadamente, $75 \%$ são orientados para o fortalecimento bélico da já longeva e ineficaz "guerra contra as drogas", que cada vez mais toma o caráter de "luta antinarcoguerrilha" na nomenclatura de Washington.

O Plano C do "Plano Colômbia" corresponde ao aporte europeu para a paz e busca contribuir para o melhoramento das condições sociais das regiões onde o Estado está menos presente. A Europa tende a não resolver nada, a não ser compensar os custos de políticas erradas, particularmente aquelas induzidas por Washington. Esse componente não é novo: a Europa sempre prometeu "outro" aporte - aquele feito a partir dos anos 90, através de um limitado Sistema de Preferências Andino/Drogas; "outra" visão - a de co-responsabilidade em matéria de drogas; e "outro" espírito - a favor dos direitos humanos e da paz dialogada. E, como em outros momentos, não há muito que se esperar dessas promessas; são sempre superadas pelas ações. A contribuição estatal européia tem sido mais simbólica do que prática. A Mesa de Doadores reunida em Madri, em julho de 2000, corroborou essa posição: somente Espanha (US\$ 100 milhões) e Noruega (US\$ 20 milhões) comprometeram recursos para o "Plano Colômbia". Meses mais tarde, a União Européia decidiu conceder 105 milhões de euros para o período 2000-2006 como forma de apoio institucio- 


\section{Juan Gabriel Tokatlian}

nal ao processo de paz e com a finalidade de contribuir para a defesa dos direitos humanos, a proteção ambiental e a substituição de cultivos ilícitos. A presença diplomática, material e estratégica européia tem sido, e continuará a ser, muito menor do que a de Washington.

Nesse contexto, a Colômbia parece necessitar com urgência de um Plano D: um plano que seja capaz de resolver definitivamente, e não somente conter no curto prazo, a guerra que padece. Esse Plano D deveria ser ajustado entre os colombianos e contar com o apoio dos latino-americanos. A Colômbia necessita terminantemente de um acordo como o de Contadora. Um "Acordo de Contadora" que valorize a negociação e o compromisso em vez de armas e promessas. Um "Acordo de Contadora" que se inicie no Cone Sul e reverta o silêncio da América Latina e a paralisia da América do Sul.

Um Plano D político é imperioso porque nem a maciça assistência militar dos Estados Unidos nem a distante participação européia prometem resolver a situação existente. Um "Acordo de Contadora" para a Colômbia precisa transcender o plano estatal: é indispensável uma aliança entre a sociedade civil colombiana não armada, os atores políticos e sociais latino-americanos influentes, os setores democráticos nos Estados Unidos e grupos progressistas europeus. Dessa forma, a crise da Colômbia poderia ser repolitizada: voltar a politizar o comportamento do Estado e a conduta da guerrilha. Esta opção, mesmo que ainda não tenha sido genuinamente experimentada, pode facilitar uma saída potencial para uma guerra desoladora.

\section{Clinton e a Colômbia}

É inquestionável que o conflito armado na Colômbia tem uma dimensão internacional relevante. As possibilidades de paz e guerra estão condicionadas por aspectos externos (consumo crescente de drogas nas nações mais industrializadas, fornecimento maciço e clandestino de armas, a política externa dos Estados Unidos, o auge do 
crime organizado transnacional, a incerteza institucional em toda a área andina, os atritos recorrentes com os países vizinhos), enquanto o drama humanitário interno tem impacto regional e ressonância mundial cada vez maior. No entanto, destacar a magnitude da tragédia colombiana não pode justificar nenhum tipo de ingerência militar, mas sim deve motivar uma intervenção política planejada. A Colômbia necessita de um novo "Acordo de Contadora", isto é, um amplo apoio diplomático com liderança da América do Sul e uma solução política negociada.

A urgência de um "Acordo de Contadora" para a Colômbia deve ser avaliada no marco de uma situação estratégica inovadora naquela zona. Nesse sentido, a presença de Bill Clinton em Cartagena no final de agosto de 2000, no contexto de uma visita de 10 horas à Colômbia, simbolizou o ponto de partida do traçado de uma delgada linha: os Estados Unidos pretendiam ampliar sua esfera de influência para mais além da baía do Caribe. O encontro entre Bill Clinton e Andrés Pastrana selou uma situação estratégica, mais do que uma relação individual, inaugurando um novo momento nas relações interamericanas. De fato, esse breve encontro de cúpula teve como conseqüência múltiplas mensagens, para audiências distintas, apresentadas sobre um pano de fundo comum: o caso Colômbia está definitivamente politizado e ali se desenrola uma complexa luta pelo poder que transcende as fronteiras da nação.

Em termos da política doméstica, o presidente Clinton situou o conflito colombiano e seu efeito para a segurança dos Estados Unidos como de alta visibilidade pública; mostrou que é capaz de usar mão pesada na "guerra contra as drogas"; buscou fixar uma política de Estado (bipartidarista, integral e de largo alcance) para o caso colombiano e tranqüilizar aqueles que viam no tratamento dado à Colômbia o início de um novo Vietnã. Em termos das relações entre Washington e Bogotá, a visita fortaleceu Pastrana no âmbito interno, porém restringiu sua margem de manobra externa no médio prazo; representou um forte golpe 
político contra a guerrilha; e legitimou uma crescente ingerência dos Estados Unidos nos assuntos colombianos.

Em termos regionais, a viagem reafirmou a preferência dos Estados Unidos pelo unilateralismo em matéria hemisférica; enfraqueceu a cúpula de presidentes sul-americanos, organizada pelo Brasil na época; contribuiu para a identificação da Colômbia como o maior problema de segurança da área; e reforçou a crescente militarização andina e amazônica para conter as conseqüências da crise colombiana.

Em verdade, o fundamental é que Washington, que já domina o seu mare nostrum caribenho, agora busca o controle efetivo dos Andes, nessa "terra nossa" da América do Sul ${ }^{7}$. Dessa forma, a definição de alianças e equilíbrios nessa zona é chave. Os Estados Unidos estão forçando um "cordão sanitário" ao redor da Colômbia com o apoio resignado do Panamá e do Equador e o respaldo ambivalente do Peru. O Panamá, que é um aliado estreito dos Estados Unidos, já armou suas fronteiras. O Equador, que vive uma delicada situação interna e que optou pela dolarização de sua economia, aceita de facto o Plano Colômbia de Washington porque assim garante para si US\$ 81,3 milhões: US\$ 20 milhões para ações antidrogas e US\$ 61,3 para o melhoramento do sistema de radares do aeroporto Eloy Alfaro.

Entre os países pequenos mais próximos da Colômbia, os Estados Unidos contam com respaldos implícitos e explícitos. Por exemplo, a Nicarágua, vizinho marítimo da Colômbia, se vale da situação para fazer suas reivindicações sobre o Arquipélago de San Andrés e Providencia, cuja soberania é colombiana, onde são produzidas células separatistas. Jamaica, Honduras, Haiti, Costa Rica e República Dominicana - cada vez mais afetadas pelo narcotráfico -, também vizinhos marítimos da Colômbia, não questionam nem o Plano Colômbia nem a militarização do Grande Caribe impulsionada por Washington com o argumento da luta contra as drogas. Rumo ao norte da Colômbia, em áreas não contíguas, a perspectiva não parece 
consoladora tampouco. Algumas ilhas do Caribe se alinharam aos Estados Unidos: Washington oferece, dentro do Plano Colômbia, US\$ 10,3 milhões e US\$ 43,9 milhões para o melhoramento dos sistemas de radar dos aeroportos Reina Beatrix em Aruba e Hato Internacional em Curaçao, respectivamente. Cuba, por sua vez, vem desempenhando um papel discreto e construtivo: Castro favoreceu uma atitude de diálogo dentro do Exército de Libertação Nacional (ELN) e trata de usar sua escassa ascendência sobre as Forças Armadas Revolucionárias da Colômbia (FARCs) para que estas evitem levar a Colômbia ao desastre. O México, de sua parte, oscila entre o respaldo e o distanciamento: nos anos recentes, a diplomacia mexicana vem buscando apartar o país da Colômbia e, assim, mostrar, com o olhar voltado para Washington, a diferença entre ambos em matéria de drogas e de insurgências.

Ao sul da Colômbia, a Bolívia (que receberá US\$ 110 milhões do Plano Colômbia e para quem Clinton solicitou o perdão total de sua dívida externa de US \$ 4,5 bilhões), em silêncio, acompanha os Estados Unidos. O Chile permanece na expectativa, sem condenar Washington categoricamente e apoiando, de fato, o Plano Colômbia. A diplomacia argentina flutua entre a assepsia e o ceticismo: formalmente apóia a paz, porém não faz muito pela Colômbia nem censura os Estados Unidos. O sul do Cone Sul está geograficamente distante da situação colombiana e politicamente pouco inclinado a criticar Washington com veemência, além do que seus interesses imediatos tradicionais não parecem estar em jogo. No entanto, esse é um erro de avaliação estratégica maiúsculo. Uma grande instabilidade vem se precipitando no mundo andino em geral, e que, mais cedo do que se pensa, afetará a região em seu conjunto.

Da mesma forma, na América do Sul, as posturas de Brasil e Venezuela, ainda que por motivos não exatamente idênticos, convergem cada vez mais. A Venezuela fortificou suas fronteiras com a Colômbia; fricções complexas e incidentes recorrentes alimentam uma si- 
tuação delicada em que se conjugam um litígio histórico no Golfo da Venezuela, recentes manifestações separatistas em províncias colombianas como Norte de Santander e Vichada e o "espírito bolivariano" compartilhado pelo presidente Hugo Chávez ${ }^{8}$ e as FARCs. No caso de Caracas, pesam hoje tanto os múltiplos problemas fronteiriços como o perigo de um efeito dominó, em meio a uma situação interna de convulsão e um desejo de se distanciar de Washington em várias frentes.

O Brasil ampliou seus dispositivos militares fronteiriços de maneira notável. Uma fronteira porosa serve a guerrilheiros e narcotraficantes igualmente, enquanto uma crescente presença de assessores norte-americanos na Colômbia põe o país sob alerta. Metaforicamente podemos dizer: traficantes e boinas verdes são igualmente percebidos como ameaças a um país que historicamente vem tendo suas fronteiras delimitadas sem dificuldades e sem perigos iminentes. Não se deve esquecer, no entanto, a enorme expansão do narcotráfico no Brasil: ali há claras manifestações de maior consumo de drogas, maior número de rotas de transporte, descobertas de mais cultivos ilícitos, mais violência urbana ligada ao crime organizado etc.

Cabe ressaltar, ainda assim, que a Colômbia não é Vietnã nem El Salvador. A intervenção militar direta dos Estados Unidos não está no horizonte imediato. O que sim cresce e se torna mais complexa é a intervenção militar indireta dos Estados Unidos acompanhada de um gradual cerco diplomático-militar à Colômbia. Porém, os colombianos e colombianas não armados não necessitam dos paradigmas Vietnã e El Salvador; a Colômbia requer um novo "Acordo de Contadora" que resolva politicamente a guerra interna nesse país.

\section{Bush e Bogotá}

As nomeações da administração do presidente George W. Bush que têm relação com aspectos-chave da política internacional e hemisfé- 
rica colocam a Colômbia em alerta e a América Latina em uma situação de reflexão necessária. O perfil de vários funcionários que têm influência significativa na conduta externa de Washington desperta inquietações e gera incertezas. As personalidades, os antecedentes e as opiniões dessas pessoas apontam para um retrocesso em matéria de paz e sugerem ambigüidades em matéria de narcotráfico. Contradição e teimosia misturam-se, o que incide de forma confusa nos vínculos bilaterais oficiais, dificultando a solução de problemas vitais da Colômbia. Essa situação pode, por sua vez, exacerbar negativamente as relações interamericanas e entorpecer os avanços hemisféricos em termos de negociações comerciais.

O rol de pessoas importantes ocupando posições de tomada de decisão, pode ser dividido em seis categorias. Na primeira estão os cruzados, como John Ashcroft (secretário de Justiça), Asa Hutchinson (diretor do DEA) e John Walters (czar antidrogas), que constituem uma espécie de extremistas morais que desejam que a Colômbia lute uma "guerra contra as drogas" até que caia o último colombiano. Na segunda estão os recalcitrantes, como John Negroponte (embaixador na ONU), Otto Reich (subsecretário para Assuntos Hemisféricos do Departamento de Estado) e Roger Noriega (embaixador na OEA). Os dois primeiros têm um passado marcado pela promoção ardorosa e clandestina dos contras nicaragüenses e por uma reconhecida falta de respeito pelos direitos humanos. O único mérito de Noriega é o de ter sido o braço direito do ultraconservador republicano pela Carolina do Norte, Jesse Helms, que encabeçou até maio de 2001 a poderosa Comissão de Assuntos Exteriores do Senado.

Em terceiro lugar, sobressaem-se homens como Paul O'Neill (secretário do Tesouro) e Richard Armitage (subsecretário de Estado), cujas condutas podem afetar a seriedade da luta internacional contra as drogas. De fato, no começo de 2001, O’ Neill deixou boquiabertos os principais sócios dos Estados Unidos na Organização de Cooperação e de Desenvolvimento Econômicos (OCDE), ao afirmar que 
Washington não apoiaria mais os esforços dos membros dessa Organização para combater os "paraísos fiscais" que, como todos sabem, são os grandes epicentros de lavagem de narcodólares. Segundo fontes seguras, há tempos atrás, Armitage - que esteve vinculado à CIA nos anos 70 e ao Departamento de Defesa nos anos 80 - propôs o uso de heroína para debilitar a capacidade de combate dos comunistas na Indochina e no Afeganistão.

Em uma outra categoria, encontram-se os ortodoxos, como Condoleeza Rice (conselheira Nacional de Segurança) e Paula Dobriansky (subsecretária para Assuntos Globais do Departamento de Estado), que conservam um enfoque marcado pela Guerra Fria e centrado na Rússia e na China. A Colômbia é crescentemente percebida por esse grupo em uma chave geopolítica e em termos de uma dupla ofensiva, ideológica (marxista) e criminal (mafiosa), que visa minar o poderio dos Estados Unidos. Aqui aparecem também os falcões, como Donald Rumsfeld (secretário de Defesa) e Paul Wolfowitz (subsecretário de Defesa), que procuram garantir a unipolaridade dos Estados Unidos a qualquer preço e que parecem conceber uma regionalização do tratamento do caso colombiano de uma perspectiva mais militar do que diplomática. Por último, há que se destacar os guerreiros, como Richard Cheney (vice-presidente), que em sua condição de legislador foi um ferrenho defensor de Oliver North e da operação Irã-contras, e, em seguida, como secretário de Defesa de George Bush pai, foi o arquiteto do "bloqueio marítimo" à Colômbia em janeiro de 1990. Nesse cenário, o secretário de Estado Colin Powell aparece, pelo menos desde o início da administração de George W. Bush, como o menos belicoso e o mais moderado.

Entretanto, não se deve fazer confusão, uma vez que todos são bastante parecidos: possuem estruturas mentais e códigos referenciais mais próprios da Guerra Fria do que da globalização; são, no fundo, mais ideológicos do que pragmáticos; colocam-se, em geral, muito mais à direita do que ao centro; parecem mais inclinados à mão de 
ferro do que à ponderação; estão mais sujeitos às tentações da terrível ameaça da força do que da prudente diplomacia; olham o mundo por um prisma realista clássico e não com uma lente idealista generosa; buscam a primazia econômica, a suficiência militar e a unilateralidade política dos Estados Unidos, em detrimento de um esquema multipolar balanceado, multilateral e estável.

O futuro dos laços entre Colômbia e Estados Unidos está condicionado ao equilíbrio de poder e às estratégias de ação desses atores e suas respectivas burocracias. Nesse sentido, o horizonte que se vislumbra não é muito promissor. O efeito combinado das políticas de Washington em relação a Bogotá e da situação colombiana e andina sobre o sistema interamericano é notório: um futuro com violência crescente e drogas em abundância só ocasionará mais violação de direitos humanos, mais de seus lugares deslocados, mais militarização, mais degradação ambiental, mais corrupção e mais narcotráfico, assim como menos investimento, menos estabilidade, menos governabilidade, menos segurança e menos crescimento na América do Sul.

Por conseguinte, torna-se fundamental fazer um acompanhamento sistemático da política de Washington para Bogotá. A administração do presidente Bush apresentou, em 2001, para apreciação do Congresso de seu país, a Iniciativa Andina de luta contra as drogas no valor de US\$ 882,3 milhões. Esta iniciativa, que foi reduzida para US\$ 731 milhões no início de 2002 como resultado das mudanças introduzidas na Câmara de Deputados e no Senado, combina um pouco de "cenoura" (US\$ 291 milhões de ajuda econômica e social) e bastante "garrote" (US\$ 440 milhões em assistência antinarcóticos e em segurança), e reflete a continuidade entre o atual governo e o do presidente Bill Clinton, em termos de envolvimento indireto, porém contundente, na crise colombiana.

A nova estratégia republicana tem três propósitos fundamentais: consolidar a dimensão bélico-ofensiva do Plano Colômbia versão 


\section{Juan Gabriel Tokatlian}

Washington, "norte-americanizar" a guerra contra as drogas no norte da América do Sul e fixar um cordão sanitário diplomático-militar em torno da Colômbia ${ }^{10}$. Se, por um lado, essa estratégia mostra a persistente preocupação e o claro interesse americano em fortalecer a capacidade militar do Estado colombiano, por outro, pretende aprofundar, na área ao redor da Colômbia, uma política punitiva comum contra as drogas, baseada em um conjunto de proibições. (O pacote proibicionista completo tende a incluir - como já o havia feito nos casos da Colômbia e do México - exigências para uma maior criminalização, militarização, pulverização, interdição e extradição.) Finalmente, busca cooptar os aliados de Washington (Panamá, Equador e Bolívia), convencer os ambíguos (Peru) no que se refere ao Plano Colômbia, e pressionar os oponentes (Brasil e Venezuela) da estratégia norte-americana contra o narcotráfico e a insurgência, para a geração de um círculo de contenção e coerção em torno da Colômbia.

Uma análise do montante, proporções e destinatários da Iniciativa Andina corrobora o que foi afirmado aqui. A Colômbia é o maior receptor com US\$ 439 milhões, divididos em US\$ 164 milhões (37,3\%) em ajuda econômica e social e US\$ 275 milhões (62,7\%) em assistência antinarcóticos e segurança. Adicionalmente, Bogotá receberá US\$ 218,9 milhões em ajuda militar e policial como parte de diferentes componentes do orçamento dos Estados Unidos em matéria de defesa e luta contra as drogas. No total, o país receberá, em 2003, um montante de US\$ 657,9 milhões em assistência dos Estados Unidos (US\$ 493,9 milhões para o "garrote" e US\$ 164 milhões para a "cenoura")".

A Iniciativa Andina destinará também US\$292 milhões para os vizinhos do país, sendo que vários já receberam US\$222,3 milhões dos US\$ 1,319 bilhão do Plano Colômbia em marcha. O Peru, que durante o governo Fujimori havia mantido uma política ambivalente diante da crise colombiana - criticava o presidente Andrés Pastrana por haver iniciado um processo de diálogo com as FARCs e, simultanea- 
mente, vendia armas à guerrilha através das práticas corruptas de Vladimiro Montesinos, o homem predileto da CIA durante anos -, receberá US\$ 135 milhões. A Bolívia, que vem apoiando o Plano Colômbia, obterá US\$ 91 milhões. O Equador, que aceitou docilmente a política antidrogas dos Estados Unidos na região, receberá US\$ 37 milhões da Iniciativa Andina. O Panamá, que não questionou seriamente o Plano Colômbia e que constitui o elo mais fraco da cada vez mais internacionalizada guerra colombiana, receberá US\$ 9 milhões.

Os dois países mais reticentes quanto a acompanhar Washington em sua estratégia para a Colômbia, Brasil e Venezuela, receberão juntos US \$ 20 milhões. O primeiro obterá US\$ 12 milhões unicamente em assistência antinarcóticos e segurança; os US\$ 8 milhões que a Venezuela receberá, destinam-se à assistência antidrogas e à segurança.

A Iniciativa Andina, portanto, reforça o Plano Colômbia, aposta em uma visão que se concentra na repressão do negócio lucrativo das drogas nos pólos de cultivo, processamento e tráfico, e fortalece um cerco potencialmente interventor em torno da Colômbia diante da eventualidade de uma descontrolada implosão interna.

Nesse contexto, uma política previsível dos Estados Unidos para a Colômbia poderia conter duas fases ou dois componentes não necessariamente excludentes. O governo Bush pode politizar ainda mais o caso colombiano. Considerar, por exemplo, que a autêntica ameaça do país deriva de uma insurgência econômica, territorial e militar e não somente do narcotráfico e da criminalidade organizada. De fato, tudo se entrelaça e confunde: guerrilha, terrorismo, narcocriminalidade organizada. Além disso, pode pressionar o governo do presidente Andrés Pastrana para que freie o diálogo político com as FARCs e se concentre em seu combate militar. Em troca, os Estados Unidos prometem mais assistência militar, técnica e de inteligência. Para não parecer que está sabotando a paz na Colômbia, Washington 
consente que se inicie uma conversação com o debilitado ELN. Em resumo, esta primeira fase é barata: os colombianos atiram por um lado e dialogam por outro, enquanto os Estados Unidos intervêm indiretamente com mais assistência bélica, porém sem baixas militares próprias.

Se esse componente da estratégia para a Colômbia fracassar, começaria a se desenhar uma segunda fase mais abrangente. Neste caso, cresceriam as manifestações intervencionistas que teriam início com o uso mais sofisticado de tecnologia militar e de medidas proibitórias: utilização de novas armas (como se viu no Iraque, Bósnia e Kossovo); pulverizações maciças dos cultivos ilícitos; prisão de guerrilheiros, narcotraficantes e paramilitares em outros países ou fronteiras porosas do país (Panamá e Equador, preferencialmente); maior presença de mercenários camuflados em companhias de segurança privada (como já contemplado pelo "Plano Colômbia" dos Estados Unidos); incremento do número de assessores no país etc. De modo gradual, vai se legitimando uma intromissão maior e mais militarizada nos assuntos colombianos. Para tanto, Washington precisa concretizar uma coalizão ad hoc latino-americana que acompanhe sua estratégia.

\section{Depois do 11 de Setembro}

O infame ataque terrorista de 11 de setembro de 2001 contra as torres gêmeas do World Trade Center, em Nova Iorque, e contra o Pentágono, em Washington, marca o fim de uma era da política mundial e anuncia o começo de uma nova etapa nas relações internacionais. De forma trágica e simbólica o pós-Guerra Fria chegou ao fim. Este intervalo de somente uma década entre o fim da prolongada Guerra Fria e um futuro esquema que se vislumbra terminou de forma inquietante $^{12}$. 
Imediatamente, George W. Bush informou sobre o início de uma "nova guerra", cujas características principais serão sua natureza não convencional, sua extensão prolongada, quase ilimitada, seu alcance planetário e seu propósito aniquilador. Nessa apresentação - que se concretizou no contra-ataque ao Afeganistão -, dois aspectos devem ser sublinhados: primeiro, desaparece a perspectiva de se chegar a um "dia após o fim da guerra", quando os vencedores proclamam a sua vitória e se dispõem a estruturar uma nova ordem. Por ter sido Washington, e não o Conselho de Segurança da ONU, quem comunicou o início da "guerra contra o terrorismo", os Estados Unidos reservam-se o direito de avisar ao mundo quando o objetivo do confronto bélico for alcançado. Nesse sentido, vale observar que aqueles países que atuam sob uma racionalidade utilitária, buscando supostos dividendos por seu apoio aos Estados Unidos, estão equivocados: a convicção e não o oportunismo é que será eventualmente retribuído quando se chegar ao esperado fim do terrorismo.

Em segundo lugar, com seu argumento, Bush apagou a distinção entre guerra e paz. Se o confronto com o terrorismo é ilimitado no tempo e na geografia, a paz dilui-se em uma guerra constante. Entraríamos, então, em um período de Paz Quente. A Guerra Fria entre as duas superpotências, Estados Unidos e União Soviética, tinha regras de jogo precisas e pouca probabilidade de se converter em um conflito direto e maciço. A Paz Quente entre múltiplos Estados, grupos transnacionais ilegais e forças contestatórias que recorrem à violência indiscriminada, carece de regras e tem alta probabilidade de produzir um número ilimitado de vítimas.

A invocação da "guerra contra o terrorismo" internacional requer que se questione como enfrentar uma contenda não tradicional. $\mathrm{O}$ fenômeno terrorista expressa a existência de um conflito assimétrico no qual, paradoxalmente, quem tem as maiores vantagens é o ator menos poderoso; é ele quem escolhe o instrumento, o lugar, o momento e o objetivo de sua ação de força. Os Estados Unidos, como 
outros tantos países, vêm vivenciando essa condição assimétrica. De fato, a estratégia contra o terrorismo levada a efeito por Washington nos últimos quinze anos considerava e incluía a complexa dinâmica da assimetria. Seu arquiteto foi o pai do atual presidente dos Estados Unidos, George Bush, que, na qualidade de vice-presidente do governo Ronald Reagan, dirigiu em 1985 a Task Force on Combating Terrorism. As conclusões de seu relatório guiaram as políticas públicas dos Estados Unidos a partir de 1986 até setembro de 2001. Seus quatro princípios básicos eram: o terrorismo constitui uma "ameaça potencial à segurança nacional" dos Estados Unidos; os Estados que dão refúgio ao terrorismo devem sofrer as "consequiências" dessa decisão; Washington não fará "nenhuma concessão" ao terrorismo; e o governo dos Estados Unidos combaterá o terrorismo "sem sacrificar as liberdades fundamentais nem pôr em perigo os princípios democráticos".

Depois dos atentados de 11 de setembro, o modo de fazer frente ao conflito assimétrico passou a ser o centro da polêmica mundial, destacando-se duas alternativas. Um modelo que hoje parece ser privilegiado pela administração Bush filho é aquele que pretende alcançar uma simetria com o oponente. O propósito elementar é fazer com que se torne impraticável o terrorismo internacional, agora redefinido como uma ameaça letal à segurança nacional. Essa aspiração implica que o mais poderoso se torne tão pérfido como o mais fraco. Não se trata somente de melhorar a capacidade dos serviços de inteligência, incrementar a cooperação mundial na luta antiterrorista, aplicar mais sanções contra os Estados que amparam o terrorismo internacional e produzir o ostracismo dos que estimulam os grupos terroristas. Trata-se de reduzir as liberdades públicas em favor de uma eventual maior segurança, de legitimar os assassinatos clandestinos e o aniquilamento antecipado dos suspeitos de terrorismo, de desconhecer normas do direito internacional em matéria de direitos humanos e de privatizar o combate contra grupos terroristas. A conseqüência mais 
previsível seria uma redução de democracia dentro e fora dos Estados Unidos. Nesse caso, será o Huntington de "As Ondas da Democracia" e não o de "Choque de Civilizações" quem terá acertado: os avanços democráticos podem ser freados e até revertidos. A "terceira onda da democracia", da qual falava Huntington, desaparecerá nas areias da "guerra contra o terrorismo".

Um segundo modelo que tem sido observado entre especialistas europeus, por exemplo, aponta para a superação da assimetria em um prazo mais longo, não imediato, e através de meios não exclusivamente repressivos. Nesse caso, trata-se de tornar o terrorismo improvável, desnecessário e ilegítimo. Para tanto é preciso dissuasão, desenvolvimento e diálogo. A dissuasão militar e policial corresponde obviamente ao âmbito do Estado e implica em mais prevenção, mais inteligência e mais sofisticação. O efeito da dissuasão é tornar improvável o comportamento terrorista. O desenvolvimento político, social e econômico envolve o Estado e também o setor privado: se o que se deseja é tornar o terrorismo desnecessário, é preciso melhorar as condições concretas de vida de milhões de pessoas, tanto no mundo árabe como na periferia, assim como alcançar uma resposta justa para a causa palestina. Finalmente, o diálogo compete à esfera não estatal, às organizações não-governamentais, aos partidos, às igrejas, aos jovens, entre muitos outros. É urgente uma maior aproximação e comunicação entre culturas, religiões e civilizações para tornar ilegítimo o recurso ao terrorismo. A conseqüência potencial dessa alternativa pode ser a sua redução gradual e efetiva, no marco de um moderado processo de democratização de maior alcance global.

De todo modo, qualquer que seja o modelo que impere para tratar dos conflitos assimétricos, o cenário estratégico da Colômbia mudou drasticamente depois de 11 de setembro. A Colômbia passou a ser a principal referência de insegurança hemisférica. Os colombianos terão cada vez menos tempo para definir seu conflito armado em termos políticos e sofrerão mais pressões para redefini-lo em termos 
criminais. Ou se preserva um espaço para reiniciar uma negociação notadamente distinta com uma guerrilha de origem marxista que preserva sua condição de interlocutor político, ou se consolidam as condições para estimular um confronto essencialmente militar contra o inimigo terrorista de qualquer linha ideológica.

Na área externa, os limites e alcance de uma e outra opção na Colômbia serão dados por três fenômenos. Primeiro, será preciso observar os resultados finais da ação militar dos Estados Unidos no Afeganistão. É provável que, além de um ataque maciço com expressivo desdobramento tecnológico, venhamos a assistir a uma nova modalidade de confronto armado que combine elementos de guerra convencional e de guerra de guerrilha no marco de uma operação prolongada. Se esse exercício de força for bem-sucedido no que tange aos objetivos alcançados - desarticulação dos enclaves terroristas - e à legitimidade lograda - sua proporção e precisão recebem amplo respaldo mundial -, seu uso em outros países identificados com territórios férteis para o terrorismo será bem possível.

Segundo, será necessário analisar, detalhadamente, os debates em Washington a respeito do Plano Colômbia, logo após a primeira fase de contra-ataque ao terrorismo internacional iniciada pelos Estados Unidos. Nesse sentido, não é improvável que o Plano Colômbia abandone sua natureza de plano antidroga, de acordo com o que foi solicitado pelo Executivo e aprovado pelo Legislativo em 2000, e se transforme em um plano antiterrorista cujo propósito mais explícito seja combater as FARCs e o ELN, e também as ultradireitistas Autodefesas Unidas da Colômbia (AUC).

Terceiro, será indispensável avaliar o uso do Tratado Interamericano de Assistência Recíproca (TIAR) revivido pela resolução da OEA de 21 de setembro em apoio aos Estados Unidos. Deve-se meditar longamente sobre o renascimento inesperado desse tratado de 1947, especialmente no que se refere aos seus artigos 3 e 6 , sobre o que o 
Órgão de Consulta considera como um ataque contra os membros do sistema interamericano de defesa e sobre as agressões a um Estado que não um ataque armado, que poderiam eventualmente ser invocados no caso de um agravamento descontrolado da crise colombiana.

Nesse sentido, apresentam-se duas questões: por um lado, se a Colômbia não avançar na solução de seu conflito armado, o país ficará definitivamente sujeito a forças e fatores externos alheios ao seu controle; por outro, se a América do Sul mantiver o desdém atual diante do caso colombiano, a lógica implacável da "guerra contra o terrorismo" no coração do subcontinente prevalecerá.

\section{Das Filipinas à Colômbia?}

Sempre que se produz uma ruptura em um processo negociador que envolve um conflito armado pelo poder, a população civil não combatente perde e os fortes de um e de outro grupo se impõem. O exemplo israelense-palestino é eloqüente. O caso da Colômbia não é uma exceção. Nesse vértice da América do Sul, o fim do diálogo governo-FARCs em fevereiro de 2002 significa que chegou a hora dos "falcões". Ninguém pensa em sentar para negociar outra vez, e sim em como aprofundar a guerra.

De um lado, estão segmentos do sistema: setores da classe política, as Forças Armadas e o paramilitarismo; de outro, os grupos mais intransigentes da guerrilha que reafirmam sua postura em favor da guerra. Uma fração da elite - em especial os criadores de gado, os latifundiários e os "novos ricos" do narcotráfico - sente que não é hora de reformas sociais e sim de levar o país a uma cruzada antiinsurgente. Uma parte da classe política - o liberalismo ligado ao candidato à Presidência Alvaro Uribe e o conservadorismo mais ortodoxo, por exemplo - parece apostar em uma política de mão pesada. A maior parte das Forças Armadas considera que com o apoio bélico maciço de Washington e a fadiga dos cidadãos em face de um processo de diálo- 
go que não tem produzido avanços nos últimos três anos, terão agora respaldo interno e externo suficiente e contarão com a necessária autonomia política para derrotar a "subversão comunista". Os paramilitares percebem que ninguém lhes colocará freio e que têm carta-branca não só para conter a guerrilha como para reverter a influência regional da mesma, perpetrando mais massacres e assassinatos atrozes.

A guerrilha, por sua vez, incrementa práticas menos "revolucionárias": crescem os sequiestros de civis, a chantagem às empresas localizadas em sua área de influência, o recurso ao negócio das drogas e o ataque indiscriminado a centros urbanos. Nesse contexto, a guerra na Colômbia terá cada vez menos princípios, ao mesmo tempo que a paz é postergada para quando todos os grupos estiverem exauridos ou tornados ainda mais ilegítimos.

Nesse contexto o papel dos Estados Unidos é crucial. Ao entrar em colapso o processo de negociação entre o governo do presidente Andrés Pastrana e as FARCs, diferentes cenários se esboçam como alternativas para entender em que direção vai o conflito armado colombiano e qual será a política de Washington a respeito. Para alguns, a imagem mais provável é a do Vietnã, com os Estados Unidos diretamente envolvidos na guerra interna de um país sul-americano. Para outros, a imagem possível é a de El Salvador: Washington oferece ajuda maciça e intervém indiretamente na crise do país. Para outros, ainda, a imagem concebível é a de Ruanda: "senhores da guerra" (warlords) envolvidos em um conflito atroz e uma ingerência tardia dos Estados Unidos por motivos humanitários.

Essas imagens poderiam ser verossímeis, porém se incluem em uma visão típica da prolongada Guerra Fria ou do breve pós-Guerra Fria; não contemplam as mudanças ocorridas na política exterior e de defesa dos Estados Unidos depois de 11 de setembro de 2001. De agora em diante, a guerra colombiana será identificada, para Washington, 
no marco do combate mundial contra o terrorismo. Nesse sentido, o caso mais semelhante ao da Colômbia não é o Afeganistão e sim, talvez, as Filipinas.

A "guerra contra o terrorismo", iniciada de forma enérgica contra o Afeganistão e liderada cada vez mais solitariamente pelos Estados Unidos, tem hoje nas Filipinas um novo cenário de confrontação. Os presidentes George W. Bush e Gloria Arroyo acordaram o envio de 650 soldados americanos para apoiar as Forças Armadas filipinas em sua luta contra o movimento armado Abu Sayyaf ("Espada de Deus" em árabe). Do compromisso bélico de Washington com a política antiinsurgente filipina, cabe ressaltar cinco características: 1) identifica-se o Abu Sayyaf como estreitamente ligado ao terrorismo internacional, neste caso com fortes conexões com a Al Qaeda; 2) o Abu Sayyaf recorre usualmente ao seqüestro, inclusive de cidadãos norte-americanos; 3) o enfrentamento militar concentra-se geograficamente no sul do país; 4) as ações desenvolvidas pelo contingente norte-americano não implicam o combate contra o Moro Islamic Liberation Front e o National Democratic Front, segundo o governo filipino; 5) os Estados Unidos destinarão US\$ 100 milhões para criar uma força especial antiterrorista filipina.

O caso colombiano, em que o Plano Colômbia de Washington autoriza a presença de até 500 assessores norte-americanos e a subcontratação de empresas de segurança privada (antigamente conhecidos como mercenários), exibe características práticas e simbólicas bastante semelhantes. Em primeiro lugar, as FARCs são apresentadas, freqüentemente, como um movimento com ligações com o terrorismo internacional - com o IRA, por exemplo. Em segundo, as FARCs são o grupo que mais efetua seqüestros. Terceiro, as FARCs abandonaram a zona de distensão outorgada pelo governo em 1998, porém controlam de facto o sul do país há muitos anos. Quarto, um avanço nas negociações com o ELN poderia levar o governo colombiano a não solicitar ajuda militar direta de Washington para combater esse 
movimento e, dessa forma, centralizar o enfrentamento contra as FARCs. E quinto, a Casa Branca acaba de solicitar ao Congresso uma assistência de US\$ 98 milhões para que tropas norte-americanas treinem as Forças Armadas colombianas na proteção da infra-estrutura do país.

Diante dessas semelhanças, as perguntas evidentes giram em torno de quem será a Gloria Arroyo colombiana; quais serão as implicações diplomáticas de um maior envolvimento militar direto dos Estados Unidos na Colômbia; o que significa essa situação em termos da despolitização do conflito armado e a subseqüiente criminalização definitiva das FARCs; e se Forças Armadas nacionais se converterão na retaguarda de um contingente armado norte-americano.

\section{A Título de Breve Reflexão Final}

Em resumo, para que a Colômbia não se converta em laboratório de experimentação de modalidades de intervenção militar, nossos países - em especial os da América do Sul - devem assumir o papel de protagonista na solução da crise colombiana pela via diplomática. $\mathrm{O}$ país merece e necessita hoje do tipo de solidariedade política que prevaleceu na América Central quando do Acordo de Contadora e não da superioridade militar que a OTAN empregou no Kossovo, nem de elucubrações que levem a invocar o TIAR, e muito menos da possibilidade de que os setores mais recalcitrantes de Washington instalem um cenário adicional, o da "guerra contra o terrorismo" na América do Sul. Tais comportamentos pressagiam somente mais insegurança humana na Colômbia e menos segurança regional. 


\section{Notas}

1. Sobre a noção de esfera de influência, ver, entre outros, Keal (1983).

2. Sobre o fenômeno dos failed states, ver, entre outros, Dorf (1996); Gros (1996); Norton e Miskel (1997); Woodward (1999) e Thürer (1999).

3. Todos os dados aqui mencionados são oriundos de relatórios públicos colombianos e internacionais. As cifras são provenientes de documentos oficiais de entidades tais como a Procuradoria, a Promotoria, a Defensoria Pública, a Chancelaria, bem como de organizações não-governamentais colombianas, como a Fundação País Livre e a Comissão Andina de Juristas, e de instituições como a Anistia Internacional, Human Rights Watch, entre outras.

4. "Cenoura" aparece aqui como a tradução literal da palavra original usado pelo autor "zanahoria". Optei pelo uso da palavra exata em português porque não se trata de traduzir uma expressão idiomática. O autor usa "zanahoria" como metáfora: a cenoura que é mostrada ao animal como estímulo para que ele se movimente em sua direção, tentando alcançá-la. A palavra "zanahoria" é usada para identificar o componente do plano que se destina à ajuda social, à busca de saídas negociadas entre Estado e comunidade [N.T.].

5. As cifras da assistência norte-americana à Colômbia podem ser analisadas em Serafino (2001).

6. No final do governo do presidente Virgilio Barco (1986-1990), e diante do crescimento do fenômeno das drogas e da violência que lhe é própria, o mandatário apresentou o Programa Especial de Cooperação (PEC) de US\$ 1,774 bilhão. O principal propósito do PEC era fortalecer o Estado colombiano e lograr o apoio das nações mais desenvolvidas na luta contra os narcóticos. O país aportava 33,2\% (US\$ 590 milhões) e solicitava à comunidade internacional 66,8\% (US\$ 1,184 bilhão). Os Estados Unidos responderam com sua tradicional combinação de "garrote" e "cenoura", por um lado, e com a retórica da co-responsabilidade da oferta e demanda, por outro. O então secretário de Defesa da administração Bush pai, Richard Cheney, pôs em prática, em janeiro de 1990, um “bloqueio marítimo" à Colômbia, depois da invasão ao Panamá. Da mesma forma, entre 1989 e 1999, Washington brindou Bogotá com US\$1,388 bilhão em assistência contra as drogas e em segurança. Paralelamente, em 1991, o Congresso dos Estados Unidos aprovou uma Lei de Preferências Comerciais Andinas (ATPA) por dez anos para estimular o crescimento da economia legal sobre a ilegal. Por sua vez, o então "czar" antidrogas William Bennett prometia um combate decisivo contra as drogas, ainda que nos anos 90 os Estados Unidos tenham dedicado, em média, apenas $32 \%$ do seu orçamento para a redução da 


\section{Juan Gabriel Tokatlian}

demanda. A Europa, por seu lado, aprovou, em 1990, um limitado Sistema Geral de Preferências-Andino por quatro anos renováveis. A América Latina não fez muito pelo país, somente a Argentina de Carlos Menem se juntou à repressão antidrogas através da entrega de aviões Pucará. A Colômbia, por sua vez, seguiu aplicando a extradição até que foi proibida constitucionalmente: quinze nacionais foram enviados para os Estados Unidos durante 1989-1990. O país erradicou quase 220 mil hectares de cultivos ilícitos entre 1990 e 1998. Ademais, os dois cartéis, de Medellín e Cali, foram perseguidos e desmantelados. Porém, o Estado não se fortaleceu. Pelo contrário, debilitou-se ainda mais: cresceu a violência, a violação dos direitos humanos e o poder de todos os atores armados. Com o ressurgimento da ameaça gerada pelo fenômeno das drogas e do inédito poderio insurgente, a Colômbia voltou a lançar um SOS à comunidade internacional com o objetivo, mais uma vez, de fortificar o Estado. O Plano Colômbia da administração do presidente Andrés Pastrana (1998-2002) é quatro vezes maior do que o PEC - o país aporta agora 53\% dos US\$ 7,5 bilhões do Plano e as nações mais industrializadas os $47 \%$ restantes. Os Estados Unidos responderam com seu próprio Plano Colômbia de US\$ 1,319 bilhão. Já o aporte europeu, como sempre, é muito menor. A contribuição latino-americana é inexistente; nem sequer propõe uma análise mais lúcida. O novo governo de George W. Bush e Richard Cheney desenhou a Iniciativa Andina de US\$ 882 milhões como continuidade ao Plano Colômbia. O Congresso americano, por sua vez, volta a discutir o prolongamento da ATPA, enquanto os orçamentos nacional e internacional antidrogas de 2002 contemplam somente $31 \%$ dos US\$19,2 bilhões para a redução da demanda. Adicionalmente, o novo "czar" antidrogas, John Walters, que foi a mão direita de Bennett, surge como um cruzado renovado na "guerra contra as drogas". A Colômbia voltou a aplicar a extradição, que foi novamente instaurada em conseqüência da reforma constitucional. Somente entre 1999-2000, o país erradicou, aproximadamente, 105 mil hectares de cultivos ilícitos. A luta contra mais de 200 redes de narcotraficantes sofisticadas, porém menos visíveis, continua. No entanto, o colapso estatal parece menos remoto. A Colômbia está experimentando o eterno retorno de uma estratégia falida, algo que muitos já reconhecem quando estão em ambiente fechado, mas sobre o que dissimulam quando estão em público, tanto no país como no exterior. Os Estados Unidos ergueram sobre sua própria sociedade e sobre a Colômbia um círculo vicioso, não eficaz, visando superar o problema das drogas: hoje o negócio mundial dos narcóticos é mais lucrativo, violento, ampliado e reacionário do que há uma década.

7. Cabe recordar que das 39 ocasiões em que os Estados Unidos usaram suas Forças Armadas em nosso Continente, no século XX, em 38 oportunidades o fizeram na baía do Caribe e somente uma (em 1986, na Bolívia, quando da Operação Blast Furnace) na América do Sul. A esse respeito, ver Grimmett (1999). 
8. Em geral, os revolucionários e as revoluções aspiram propagar-se além do marco específico de uma nação. O ideal revolucionário tende a ser grandioso em sua forma, conteúdo e alcance. Inicialmente, a Revolução Francesa nasceu com uma paixão de transcendência universal. Na sua origem, a Revolução Bolchevique teve o anseio de difundir-se pelo mundo, além das fronteiras russas. Em um tempo mais recente e num âmbito mais hemisférico, a Revolução Peronista na Argentina dos anos 40, a Revolução Cubana depois de 1959 e a Revolução Sandinista nos anos 70, imaginavam projetar-se além dos limites nacionais. Estas e muitas outras revoluções foram atos fundacionais: tratava-se de estabelecer uma nova ordem política interna. Todas as revoluções pretendem expandir-se em direção às suas vizinhanças e até os lugares mais remotos. Mas é certo que, mais cedo ou mais tarde, os revolucionários entendem que a sobrevivência da revolução nacional depende, entre outras coisas, de assegurar de forma sensata o poder interno e limitar sua irradiação de forma casual para o exterior. Na Venezuela atual está se produzindo uma Revolução Bolivariana, comandada por Hugo Chávez, através de uma espécie de democracia plebiscitária. Como todo fenômeno revolucionário, implica a aparição de um novo protagonista social com pretensão de plena hegemonia. Trata-se, no melhor dos sentidos, do maior gesto revolucionário popular dos Andes em décadas, liderado por um caudilho populista e heterodoxo, e protegido pretorianamente por suas forças militares. O projeto chavista profetiza abertamente seu sonho de difusão no coração andino da América do Sul. América Latina e Estados Unidos enfrentam o desafio de não reproduzir no caso da Venezuela a experiência de isolamento e perseguição a que submeteram Cuba. O fenômeno Chávez deve ser entendido primeiro e em seguida ponderado; nem a agressão nem a marginalização serão alternativas favoráveis para a estabilidade e o pluralismo venezuelanos no médio e longo prazos.

9. Ver nota 4.

10. Torna-se fundamental compreender a base conceitual que guia a guerra contra as drogas impulsionada por Washington. Para isso, é preciso deter-se na racionalidade e não na retórica dos Estados Unidos. Neste tema, Washington orienta-se por quatro pressupostos: $1^{\circ}$ ) assume que a demanda depende da oferta, portanto, busca reprimir os centros de cultivo, produção, processamento e tráfico de narcóticos; $2^{\circ}$ ) assume que um tratamento punitivo nos pólos de fornecimento de drogas é mais efetivo em termos de efeitos (metas e conquistas) e de recursos (assistência e orçamento). Para o equilíbrio custo/benefício de Washington, resulta mais vantajoso concentrar os esforços antinarcóticos nos núcleos de oferta; $3^{\circ}$ ) assume que os efeitos de uma maior erradicação de cultivos ilícitos serão múltiplos para os produtores. Entre outros, destaca a redução do preço do cultivo ilícito nas zonas de produção, a diminuição do poder dos traficantes e a contenção da violência gerada pelo narcotráfico; $4^{\circ}$ ) assume que os efeitos de uma maior erradicação de cultivos ilícitos serão de três tipos para os 
países consumidores: menor disponibilidade, maior preço e menor potencial de pureza das drogas. Com base nesses pressupostos, é pertinente avaliar os resultados da política baseada nessa racionalidade. Nesse sentido, cabe assinalar que a Colômbia experimentou a pulverização de cultivos ilícitos com paraquat no final da administração do presidente Julio César Turbay (1978-1982). A Colômbia acelerou a pulverização maciça durante a administração do presidente Belisario Betancur (1982-1986), aplicando o glifosato para a maconha e o garlon-4 para a coca. A Colômbia continuou a erradicação química e forçada de maconha e coca durante a administração do presidente Virgílio Barco (1986-1990). Reforçou a pulverização da maconha e da coca e iniciou a destruição da papoula com glifosato durante a administração do presidente César Gaviria (1990-1994). A Colômbia bateu todas as marcas históricas nacionais e internacionais em matéria de erradicação química e manual de cultivos ilícitos durante a administração do presidente Ernesto Samper (1994-1998) e experimentou herbicidas ainda mais tóxicos, como o imazapyr e o tebuthiuron. Somente em 1998, o governo Samper (até agosto) e a administração do presidente Andrés Pastrana (1998-2002) pulverizaram 66.083 hectares de coca e 2.931 hectares de papoula, e destruíram de modo manual aproximadamente $90 \mathrm{mil}$ hectares de coca entre 1999 e 2000. Finalmente, a partir de 2000, Washington começou a pressionar Bogotá para aplicar um veneno perigoso, ofusarium oxysporum, no processo de erradicação forçada na Colômbia. Apesar de todos esses esforços, os efeitos da repressão química aos cultivos ilícitos têm sido paupérrimos. Com efeito, em 1981, a Colômbia tinha 25 mil hectares de maconha e coca plantados. Em março de 2001, o relatório anual do Departamento de Estado dos EUA sobre drogas - International Narcotics Report - mostrou que na Colômbia existiam 138 mil hectares cultivados, somente com coca. Em 1990, a produção de heroína era insignificante; em 1996, o país já produzia 63 toneladas e hoje a Colômbia já superou o México como o principal fornecedor hemisférico de heroína. Enquanto em 1998 a produção colombiana de cocaína foi de 435 toneladas, em 1999 alcançava 520 toneladas e em 2000 chegou a 580 toneladas. Nos anos 80, a Colômbia tinha uma classe criminosa emergente; hoje vive as conseqüências de uma narcocriminalidade enriquecida, violenta e desafiante. Porém, a situação colombiana não é excepcional e extravagante. Apesar dos anos de erradicação forçada e química de plantações ilícitas no mundo, no último relatório do Escritório das Nações Unidas para o Controle de Drogas e Prevenção do Crime - Global Illicit Drug Trends 2000 -, o cultivo de coca passou de 240 mil hectares em 1987 para 270 mil hectares em 1999, e o da papoula, de 211 mil em 1998 para 217 mil em 1999. Enquanto isso, na década de 90, 120 países comunicaram a existência de cultivos de cannabis em seus territórios. Em 1999, a produção global de heroína chegou a 580 toneladas, a de cocaína a aproximadamente 1.000 e a de maconha foi cerca de 30 mil toneladas. A esta situação se somam as cifras dos principais mercados de consumo. Em 1981, nos 


\section{Colômbia: Mais Insegurança Humana, Menos Segurança Regional}

Estados Unidos o preço do grama de cocaína era de US\$191 e a pureza de 40\%, enquanto em 1999 o preço chegou a US\$ 44 e a pureza a 70\%. Em 1981, o preço do grama de heroína era de US\$ 1.200 e a pureza de 5\%, enquanto em 1999 o preço chegou a US\$ 318 e a pureza a 25\%. Na Europa, paralelamente, em 1999, o preço do grama de cocaína foi de US\$ 90 e o de heroína US\$ 98. Em 2000, conseguiu-se mais drogas nos Estados Unidos e na Europa, de melhor qualidade e a menor preço. Em termos de demanda, a situação européia mostra sinais preocupantes de aumento, ao mesmo tempo que os Estados Unidos não mostram avanços definitivos já que ainda existem quase 14 milhões de consumidores. Nesse país, a taxa de crescimento de jovens consumidores de cocaína mostra um aumento alarmante a partir de 1997. E o consumo de maconha entre os jovens, que havia diminuído no final dos anos 80 , foi notadamente incrementado entre 1992 e 1995 e continua alto no momento. Concomitantemente, nos Estados Unidos, em 1990, o total de prisões vinculadas ao fenômeno das drogas (consumo, venda, distribuição, manufatura etc.) foi de 1.089.500, enquanto em 1996 cresceu para 1.128.647. Em 1990, o total de prisioneiros federais encarcerados por delitos ligados ao fenômeno dos narcóticos foi de 53,5\%, enquanto em 1995 se elevou para 59,9\%. Hoje, os Estados Unidos têm, em comparação com os países mais industrializados do mundo, a maior população de pessoas encarceradas por delitos relacionados com o fenômeno das drogas. Em síntese, a Colômbia já pulverizou suficientemente seu território com substâncias nocivas para a saúde de sua população e a preservação de seu meio ambiente, enquanto a demanda de drogas dos cidadãos dos Estados Unidos segue no auge e o consumo de narcóticos na Europa cresce. Uma nova erradicação química promete ser apenas um pouco mais da mesma coisa: uma vitória de pirro que não resolve a essência do negócio das drogas. As conseqüências serão também as mesmas, os custos mais altos da proibição continuarão a ser pagos pelos colombianos e os dividendos da lucrativa empresa continuarão a ser lavados nos bancos dos Estados Unidos, Caribe, Suíça e Mônaco, entre outros.

11. Sobre esses dados, consultar a informação do Center for International Policy como parte de seu Colombia Project (http://www.ciponline.org/colombia).

12. Depois dos atentados terroristas, os Estados Unidos inclinaram-se a reavaliar, ao menos parcialmente, seu comportamento externo, relegando o recurso ao unilateralismo a um segundo plano e reconhecendo o valor do multilateralismo. O contra-ataque ao Afeganistão levou a Casa Branca a invocar diversas coalizões político-diplomáticas para enfrentar a luta contra o terrorismo. Em distintos foros internacionais e em diferentes âmbitos multinacionais, Washington manifestou-se a favor de práticas mais amplas, consensuais e plurais. Na ONU e na OEA, até na OTAN, no ANZUS e na OCDE, nas Américas, na Europa e na Ásia Central, igualmente, assumindo compromissos no Ocidente e no Oriente, os Estados Unidos se mostraram interessados em fortalecer as alternativas e os 


\section{Juan Gabriel Tokatlian}

acordos multilaterais. No entanto, a expectativa de que essa nova linha de conduta dos Estados Unidos vai levar a um exercício mais sábio da hegemonia e a diminuir a tentação imperial de certos círculos políticos, empresariais e militares, não tem um contorno muito preciso. No começo de 2002, os "falcões" da administração Bush anunciaram novos ataques a países que abrigam o terrorismo. Apesar de os aliados mais próximos terem alegado que esse seria um grave erro, Washington insiste em uma estratégia de "guerra contra o terrorismo" cada vez mais individual. O governo republicano, finalmente, anunciou sua decisão de denunciar o Tratado ABM, de 1972, com a União Soviética e, dessa forma, proceder ao desenvolvimento e experimentação de um escudo defensivo antimísseis. Tal medida foi rechaçada pela Rússia, China e União Européia, assim como pela Assembléia Geral da ONU. Surpreendentemente, os Estados Unidos não se mostraram favoráveis a um maior e melhor controle das armas biológicas; no início de dezembro de 2001, e em seguida a uma reunião de 144 Estados em Genebra para o estabelecimento de um acordo, Washington bloqueou a conclusão do protocolo que pretendia reforçar a Convenção sobre armas biológicas de 1972. Em resumo, Bush parece ter optado pela "Doutrina Sinatra": define "à sua maneira" o alcance do multilateralismo dos Estados Unidos. De algum modo, coloca-se em prática o que antes de 11 de setembro havia sido definido por Richard Haas, diretor do Policy Planning do Departamento de Estado, como a conduta mais pertinente para Washington: o multilateralismo "a la carte".

\section{Referências Bibliográficas}

DORF, Robert H. (1996), “Democratization and Failed States: The Challenge of Ungovernability”. Parameters, verão.

GRIMMETT, Richard F. (1999), "Instances of Use of United States Armed Forces Abroad, 1798-1999”. CRS Report for Congress, 17 de maio.

GROS, Jean-Germain. (1996), "Towards a Taxonomy of Failed States in the New World Order: Decaying Somalia, Liberia, Rwanda, and Haiti”. Third World Quarterly, vol. 17, nº 3 .

KEAL, Paul E. (1983), “Contemporary Understanding about Spheres of Influence”. Review of International Studies, vol. 9, nㅡ 3 . 
NORTON, Richard J. e MISKEL, James F. (1997), "Spotting Trouble Identifying Faltering and Failing States". Naval War College Review, primavera.

OQUIST, Paul. (1978), Violencia, Conflicto y Política en Colombia. Bogotá, Biblioteca Banco Popular.

RENO, William. (2000), "Economic Motivations of Warfare in Collapsed States". National Strategy Forum Review, inverno.

SERAFINO, Nina M. (2001), "Colômbia: U.S. Assistance and Current Legislation”. CRS Report to Congress, 13 de junho.

THÜRER, Daniel. (1999), "The Failed State and International Law”. International Review of the Red Cross, nำ 836, dezembro

WOODWARD, Susan L. (1999), "Failed States: Warlordism and Tribal Warfare". Naval War College Review, primavera.

ZARTMAN, I. William (ed.). (1995), Collapsed States: The Disintegration and Restoration of Legitimate Authority. Boulder, Lynne Rienner Publishers.

\section{Resumo}

\section{Colômbia: Mais Insegurança Humana, Menos Segurança Regional}

No contexto da grave crise que atravessa a região andina em seu conjunto, o exemplo da Colômbia é o mais dramático e serve potencialmente de modelo de intervenção externa nos assuntos internos de um país do hemisfério. Nesse sentido, analisa-se o tipo de guerra que vive a Colômbia, assim como o chamado novo intervencionismo e as possíveis saídas para o conflito armado no referido país. Trata-se de uma situação complexa e instável em que se misturam e confundem guerra política, violência criminal, demolição do Estado, violação dos direitos humanos e expansão do poderio estadunidense na região. Como decorrência do aumento dos confrontos internos, da persistência da "guerra contra as drogas" e do começo da "guerra contra o terrorismo", a ingerência dos Estados Unidos é cada vez mais eloqüente e preocupante. Enquanto isso, uma América do Sul passiva não parece querer 
comprometer-se com uma saída viável para um conflito expansivo no coração dos Andes.

Palavras-chave: Região Andina - Insegurança Humana - Ingerência dos Estados Unidos - Colômbia

\section{Abstract}

\section{Colombia: More Human Insecurity, Less Regional Security}

The Colombian predicament, characterized by foreign intervention in the domestic issues of a country in the Southern hemisphere, can be considered the most dramatic crisis amongst the various crises in the Andes region. The author analyzes the kind of war that exists in Colombia, as well as the so-called new interventionism and the possible solutions of the conflict in that country. It is a very complex and unstable situation in which political war, criminal violence, the destruction of the state, violation of human rights and the expansion of US power are all mixed. The intervention of the US in Colombia as a consequence of growing domestic conflicts, the continuation of the "war against drugs" and the beginning of "the war against terrorism," is increasingly evident and worrying. Meanwhile, a passive South America does not seem to be willing to engage itself in the search for a viable solution to an expanding conflict in the heart of the Andes.

Key words: Andes Region - Human Insecurity - US Intervention Colombia 